Ethiopian Journal of Environmental Studies \& Management 9(3): 354 - 371, 2016.

ISSN:1998-0507

doi: http://dx.doi.org/10.4314/ejesm.v9i3.9

Submitted: February 08, 2016

Accepted: May 13, 2016

\title{
GOVERNING AGRICULTURAL DROUGHT: MONITORING USING THE VEGETATION CONDITION INDEX
}

\author{
*TAGEL GEBREHIWOT.,1 ANNE VAN DER VEEN.² AND BEN MAATHUIS ${ }^{2}$ \\ ${ }^{1}$ Environment and Climate Research Centre (ECRC) / Ethiopian development Research \\ Institute (EDRI), P. O. Box 217, Addis Ababa, Ethiopia \\ ${ }^{2}$ Faculty of Geo-Information Science and Earth Observation (ITC), University of Twente, \\ P. O. Box 217, 7514 AE Enschede, The Netherlands
}

\begin{abstract}
This paper investigates the spatial and temporal aspect of seasonal agricultural drought in Ethiopia during the cropping season using Vegetation Condition Index. SPOT-VGT S10 NDVI time-series for the period 1998 to 2013 was employed. Five hundred and sixty-seven dekadal images were administered in order to produce the multi-temporal agricultural drought maps. Accordingly, the analysis showed different causes for the nation-wide drought events occurred in the years 1998, 2000, 2002, 2009, and 2010. The study provides key information on the major historical agricultural droughts in Ethiopia by differentiating over the crop cycles and is able to geographically identify the regions most exposed to recurrent cycle of drought events.
\end{abstract}

Key Words: Drought, Vegetation, Remote sensing, NDVI, VCI

\section{Introduction}

Agriculture remains the basis of livelihood for majority of the Ethiopian population. The Ethiopian economy depends mainly on the performance of the agricultural sector, which contributes about 40 per cent of the Gross Domestic Product (GDP), 85 per cent of employment, for about 90 per cent of rural peoples income (Diao, 2010). Crop production is predominantly subsistent, largely rain-fed and often unreliable. As a result, crop production is highly exposed to seasonal shifts in climate (Conway and Schipper, 2011).

In Ethiopia, recurrent cycle of drought and extreme reliance on rain-fed agriculture has been the main causes of food shortages and household food insecurity. Based on Wardlow et al. (2012), drought is a natural hazard with effects that accrue over an extended period of time. It can be broadly categorized as being agricultural, meteorological, hydrological, and socioeconomic drought (Dracup et al., 1980; Wilhite, 2000; Boken, 2005). In Ethiopia, drought is considered to be a meteorological phenomenon characterized by extended periods of precipitation deficit. Accordingly, this study focuses primarily on drought, which simply refers to a period characterized by the lack of precipitation for a period of time and consequent crop failure due to soil moisture deficit (Boken, 2005). According to Heim (2002), agricultural drought is generally a short-term dryness, but occurs at a critical time during the crop growing season and can adversely impact crop yields. 
Gray and Muller (2012) reported that drought is a significant negative shock that can undermine the livelihood of the people, who depend on agriculture. Over the past three decades, Ethiopia has been overwhelmed by climate variability and associated droughts that resulted profound effects on the country's food production and employment (Benson and Clay, 1998; Bewket and Conway, 2007; Araya and Stroosnijder, 2011; Conway and Schipper, 2011; Falco, 2012). The frequent droughts in turn affected the income of the rural poor who fully depend on agriculture as droughts can result in reductions in crop outputs by as much as 90 per cent from a normal rainfall period (WFP, 2009).

Over the past decades drought has become more frequent in both size and frequency due to variability in climate (Ferris-Morris, 2003; Gebrehiwot and van der Veen, 2013). Different studies indicate that climate variability will affect food and water security in significant and uncertain ways over the coming decades because of agriculture's direct exposure to the variable climate (Ringler et al., 2010). According to Omondi et al. (2014), in Ethiopia, the warm extremes are increasing while cold extremes are decreasing. This warming is dangerous for agricultural practices (Collier et al., 2008). Robinson et al. (2013) reported that drought shocks are expected to be more frequent and pronounced in the future. Furthermore, strong indications are available that rural population in developing countries, from whom agricultural production is the primary source of employment, will be most affected. Provided the year-to-year climate variability and its impacts on agriculture is apparent, effective and timely monitoring of agricultural droughts is highly pertinent (Boken, 2005; Eerens et al., 2014). Better understanding of drought phenomenon and the different approaches for dealing with it will significantly help to minimize the risk of crop failure. One way to detect agricultural drought is to quantify it through standard drought indices. Subsequently, monitoring agricultural drought using standard drought indices will provide policy makers with key information on the spatial extent of drought severity triggering drought contingency plans and development of early warning systems.

Existing literature suggests two categories of drought indices that have been applied in recent decades: those derived mainly from in-situ data, and those derived from remote sensing satellites. Agricultural drought monitoring strictly requires spatially contiguous time series data to predict the surface temperature and vegetation condition, which climate-based indices have main drawbacks (Yagci et al., 2011; Tonini et al., 2012). Hence, data from remote sensing image at high temporal even at low spatial resolution can aid to assist in monitoring crop failures as they provide crucial information in near-real time over large areas as opposed to a single point measurement.

The specific objective of the study is to investigate seasonal agricultural drought conditions in Ethiopia's major crop producing regions. As a refinement of Rojas et al. (2011), we differentiated the analysis over the different crop cycles in order to get more insight on the main causes of the drought conditions during the crop growing season. For the purpose of the study, satellite-based drought indices, particularly the Vegetation Condition Index derived from SPOTVegetation NDVI time-series for the period 1998 to 2013, was employed. Furthermore, Absolute Difference Average was applied to investigate the temporal pattern of agricultural drought. To the best of our knowledge, this paper 
is the first to apply the Software for the Processing and Interpretation of Remotely sensed Image Time Series (SPIRITS), which is a recently developed software package for image time series processing for agriculture monitoring. It is believed that this study will provide policy makers with key information on drought prone areas, which is vital for decision making and implementation of localized programs that aim to reduce food insecurity in the affected areas of the country. The paper is structured as follows: section 2 describes the materials and methods employed in this research, section 3 presents the results, and section 4 and 5 presents the discussion and conclusion of the study respectively.

\section{Materials and Methods}

\section{Study Area}

Ethiopia is the second largest country in sub-Saharan Africa located in the Horn of Africa (Figure 1). Geographically, it lies between the latitudes $3^{\circ} 24^{\prime} \mathrm{N}$ and $14^{\circ}$ $53^{\prime} \mathrm{N}$, and the longitudes $32^{\circ} 42^{\prime} \mathrm{E}$ and $48^{\circ} 12^{\prime} \mathrm{E}$. The country has a complex topography with an altitude ranging from 120 meters (m) below sea level in the northeast to over $4000 \mathrm{~m}$ above sea level in the northern highlands (Engida and Esteves, 2011). As a result of Ethiopia's topography and geographic location, three distinct seasons can be recognized climatically. These seasons are the premonsoon hot season from March to May locally called Belg; the main rainy season, which lasts from June to September locally called Kiremt, and the dry winter season from October to February locally called Bega. However, the southern and south-eastern lowland of the country experience bimodal rainfall distribution, receiving rainfall from March to May and from September to October (Degefu, 1987; Diro et al., 2009).

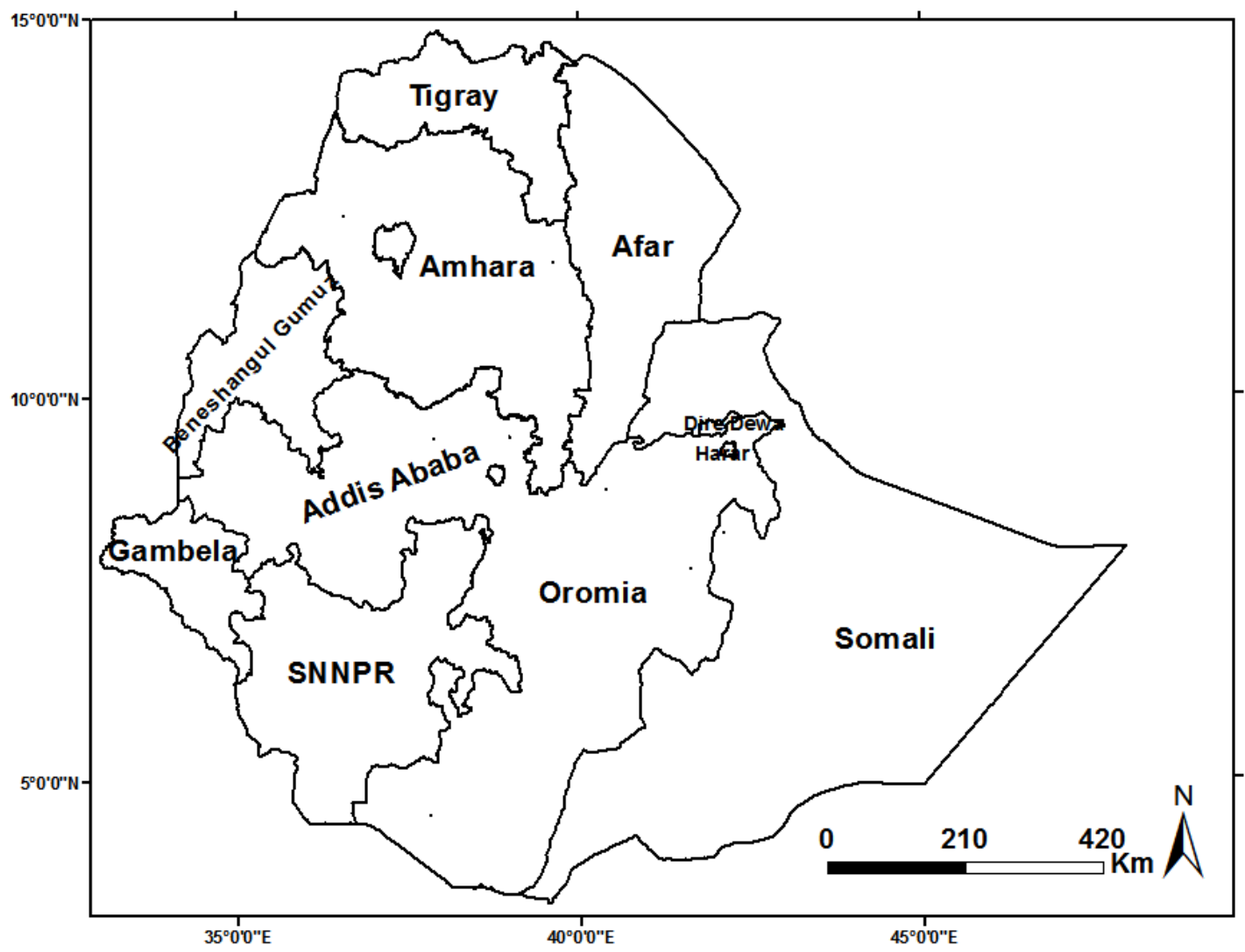

Figure 1: Administrative map of Ethiopia 


\section{Data Collection}

For this study, SPOT Vegetation 10day Normalized Difference Vegetation (NDVI) images from April 1998 December 2013 were acquired from VGT4Africa of the DevCoCast project website (http://www.vgt4africa.org). The remotely sensed SPOT Vegetation products have $1-\mathrm{km}$ spatial resolution, fully cover Ethiopia and have a 10-day temporal resolution. The satellite data recorded by SPOT Vegetation instrument are already pre-processed in order to ensure the quality of the NDVI product (Jacobs et al., 2006). According to Jacobs et al. (2006), the NDVI product can be used for crop and agricultural monitoring and early warning to detect failing crop growing seasons.

Furthermore, TAMSAT 10-day rainfall estimates (RFE) with a spatial resolution of 0.0375 degree covering the African continent were acquired from Reading University (UK) (http://www.met.reading.ac.uk/tamsat/ab out), for the period of January 1998 to December 2013. A recent study by Dinku et al. (2007) validated different satellite rainfall products and proved TAMSAT rainfall estimates to be the best for the complex Ethiopian topography. Thus, differing from Rojas et al. (2011), the spatio-temporal pattern of agricultural drought condition in the major Ethiopian crop producing areas was further investigated using TAMSAT 10-day rainfall estimates as an alternative approach.

In addition to the above mentioned datasets, two spatial datasets were used in this study. First, a land cover map, and secondly a map with Ethiopia's regional boundary. The land cover map for Ethiopia (figure 2) was extracted from the ESA Global Land Cover map of 2009 in order to locate agricultural land cover type, which was used to extract the NDVI and VCI statistics over the main agricultural land per administrative region.

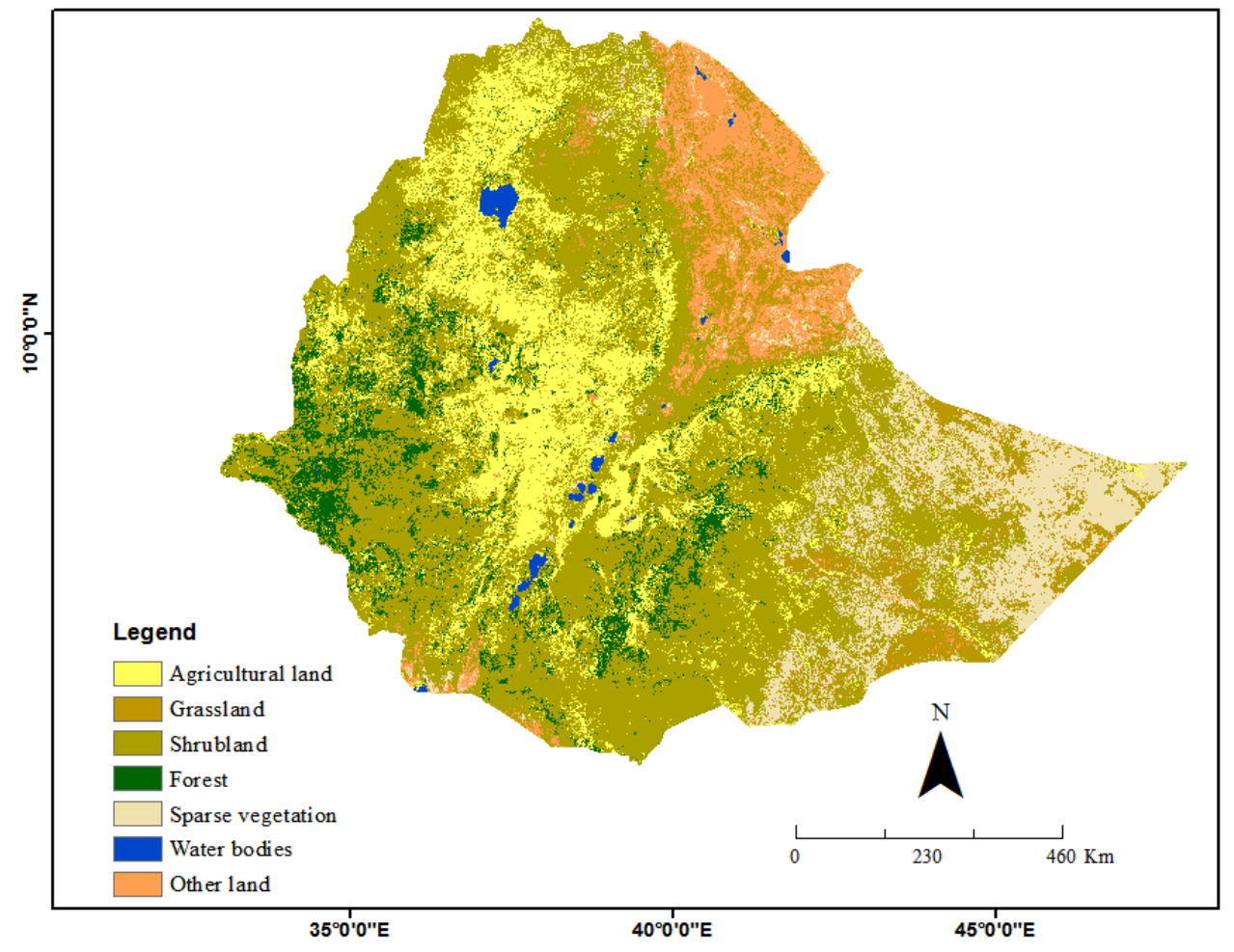

Figure 2: Ethiopia land cover map, extracted from ESA Global Land Cover map of 2009 
Vegetation Based Agricultural Drought Monitoring

Data from remote sensing image time series is an effective way to monitoring crop failures as they provide crucial information in near-real time over large areas. In recent decades, several remotely sensed based drought indices have been applied to characterize the state of vegetation and describe drought conditions (Atzberger and Eilers, 2011). Vegetation condition is a good indicator of agricultural drought and can be quantified by the NDVI index. Variability of NDVI is the most commonly applied index for monitoring vegetation and drought assessment (Tucker, 1979; Kogan, 1995b; Yang et al., 1998; Ji and Peters, 2003; Domenikiotis et al., 2004; Bajgirana et al., 2008; Zhang et al., 2013).

Consequently, NDVI-based indices have been applied to monitor vegetation state and quantify drought. Thus, different indices such as the Vegetation Condition Index (VCI) (Kogan, 1990, 1995a; Liu and Kogan, 1996; Bhuiyan et al., 2006; Gebrehiwot et al., 2011; Rojas et al., 2011); Absolute Difference NDVI (ADVI) (Tonini et al., 2012); Anomaly Vegetation Index (AVI) (Anyamba et al., 2001); and the Vegetation Health Index (VHI) (Kogan, 1995a; Rojas et al., 2011) have been applied. Moreover, it has been demonstrated that the VCI can be successfully used for monitoring crop condition (Brown et al., 2008). A review of literature further indicates that VCI is suitable for monitoring agricultural drought and provides accurate information for short-term agricultural droughts during the crop growing season (Kogan, 1995a; Liu and Kogan, 1996; Kogan, 1997; Gitelson et al., 1998; Unganai and Kogan, 1998). VCI is reported to capture rainfall dynamics better than NDVI specifically in geographically heterogeneous areas (Rojas et al., 2011). Given the potential of the VCI to detect and characterize agricultural drought episodes, VCI is employed in this study to describe the spatial-temporal variability of seasonal agricultural drought patterns in Ethiopia. It is determined as:

$$
V C I=\left(\frac{N D V I-N D V I_{\text {min }}}{N D V I_{\text {max }}-N D V I_{\text {min }}}\right) * 100
$$

where NDVI, $\mathrm{NDVI}_{\min }$, and $\mathrm{NDVI}_{\max }$ are the smoothed 10-day NDVI, its absolute long-term minimum and maximum NDVI values respectively for each pixel. VCI varies in the range of 0 to 100 per cent reflecting relative changes in the vegetation condition from extremely low to high VCI (Kogan, 1995a; Kogan et al., 2003).

A review of literature also revealed the close relationship between NDVI and seasonal rainfall variations in semi-arid land regions (Tucker et al., 1985; Rasmusson, 1988; Nicholson et al., 1990; Tucker et al., 1991). Consequently, in this study the analysis on NDVI pattern was conducted during the main crop growing season as the evolution of vegetation in Ethiopia is closely related to seasonality in rainfall, which is the basis for using NDVI time series data for agricultural drought monitoring.

NDVI for the growing period was retrieved from the 10-day NDVI images using a compositing method. Specifically, for each growing season the composite NDVI map was determined by averaging twelve 10-day smoothed NDVI images. After the production of the smoothed NDVI images for the crop growing period, the long term maximum and minimum NDVI images were produced. Consequently, the VCI for each cropping season was determined using equation (1). The VCI images for the crop growing season are then 
classified into agricultural drought condition maps using the classification method suggested by Kogan (1995a) (Table 1). Consequently, 567 dekadal images were administered to produce the temporal agricultural drought maps. The long-term statistics is extracted for agricultural land cover type only.

Table 1: VCI-based agricultural droughts classification scheme

\begin{tabular}{ll}
\hline Category name & Threshold value (\%) \\
\hline Extreme drought & $0-10$ \\
Severe drought & $11-35$ \\
Fair vegetation condition & $36-50$ \\
No drought (optimal & $51-100$ \\
vegetation condition) & \\
\hline
\end{tabular}

As a second method, Absolute Difference Average (ADav) was used to detect the temporal agricultural drought episodes. ADav NDVI is a transformation of the Normalized Difference Vegetation Index, which is calculated as:

$$
\operatorname{ADav}(y, p)=X(y, p)-\operatorname{Average}(p)
$$

where $y$ is the actual year, $p$ is the actual time interval within year $y, \mathrm{X}(\mathrm{y}, \mathrm{p})$ is the actual smoothed NDVI value for year $y$ and dekad $p$, Average ( $p$ ) is the long-term historical average for the NDVI within the same dekad $p$. A negative NDVI shift from the historical average is usually linked to a reduction in the vigor of vegetation condition. In a similarly way equation (2) was also applied to detect drought events using the 10-day TAMSAT rainfall estimate datasets. The methodological framework of the study, which is adapted from Eerens and Haesen (Eerens and Haesen, 2013) is given below (Figure 3).

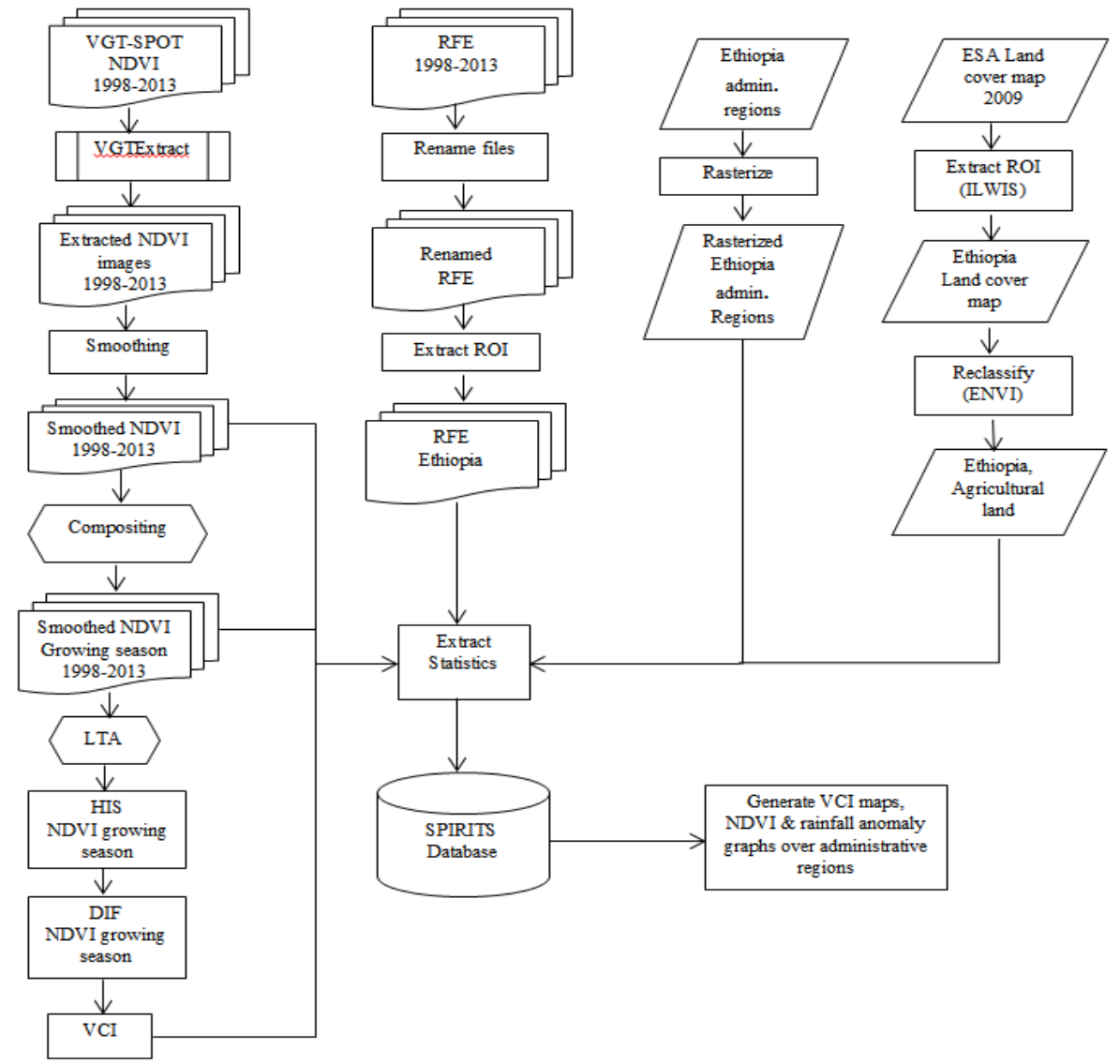

Figure 3: Methodological framework, adapted from Eerens and Haesen (Eerens et al., 2014) 


\section{Results}

\section{Temporal Agricultural Drought} Assessment using NDVI Anomaly

The temporal pattern of vegetation condition during the crop growing period was examined using ADav NDVI for the major crop producing regions in Ethiopia. Negative NDVI anomalies indicate the duration of every drought appearance during the growing period. The changes in the vegetation of two agricultural production regions in Ethiopia for the period 1983 to 2013 is shown in Figure 4 as a representative example. According to Ethiopia's rainfall seasonal character, NDVI is expected to reach maximum from mid of June $\left(20^{\text {th }}\right.$ dekad) to mid of August $\left(25^{\text {th }}\right.$ dekad $)$.
Based on the ADav NDVI anomalies several drought episodes were identified in Ethiopia, 1998, 2002, 2004, and 2009. Looking at the regional level, negative NDVI anomalies were observed in the northern highlands of Ethiopia (Amhara and Tigray regions) during the end of crop growing season of 1998, 2002, and 2009 which resulted in harvest failure (Figure 4). The temporal analysis further showed that extremely low NDVI anomalies were observed at the beginning of the cropping period during the 2000, 2003, and 2008 in Gambela region. In contrast, most of the regions showed normal vegetation conditions during the growing season of 1999, 2005, and 2013.
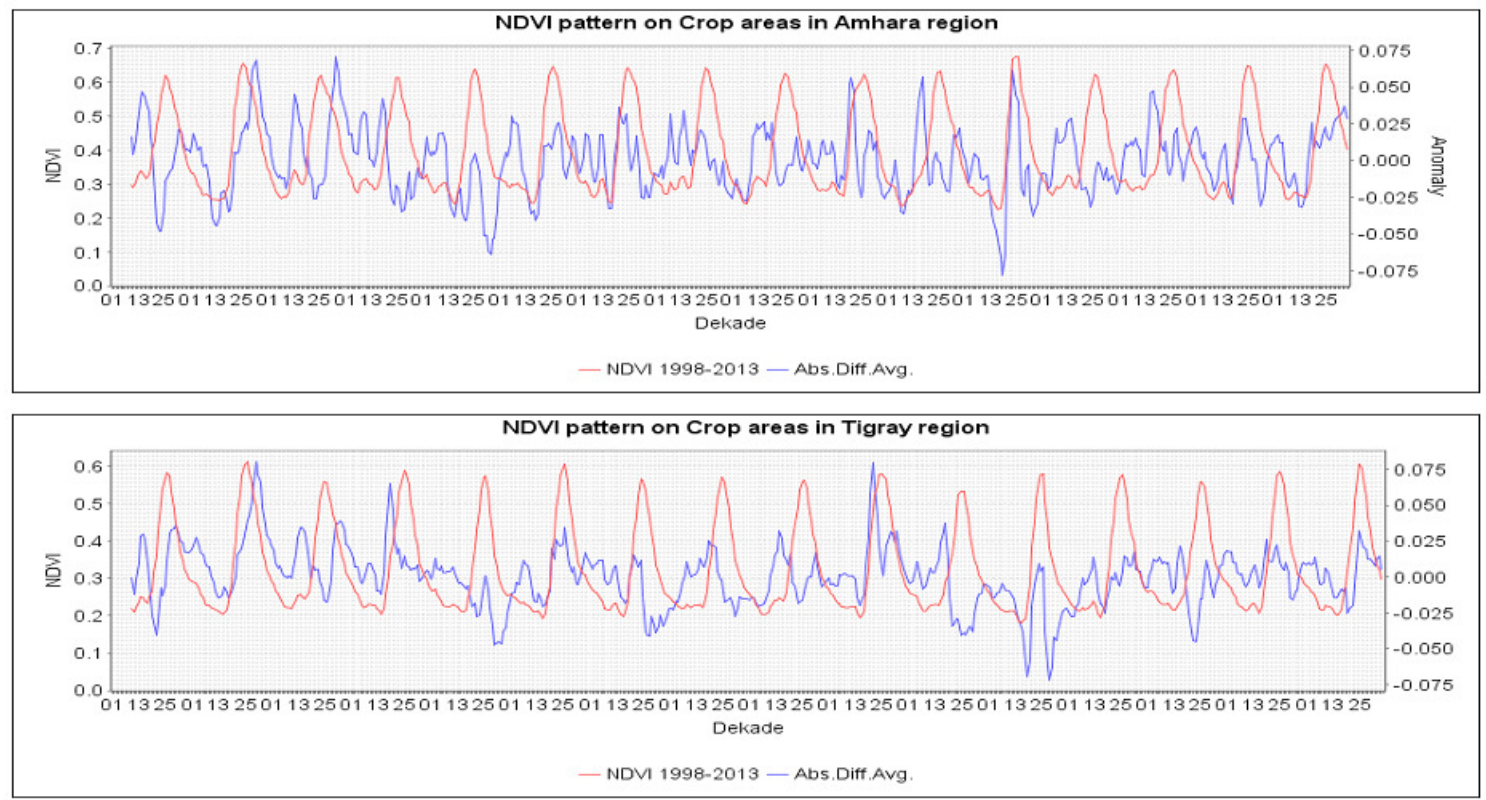

Figure 4: Temporal decadal NDVI anomaly pattern on crop areas for Tigray and Amhara regions; 1998 -2013

\section{Spatial Patterns of Drought}

The spatial VCI patterns during the crop growing season are shown in Figure 5. These series of VCI maps show the spatial and temporal persistence of agricultural drought conditions in Ethiopia over the past two decades. Examination of the temporal VCI-based agricultural drought maps clearly indicate a country-wide drought conditions during the crop growing periods of 1998, 2000, 2002, 2009, and 2010 in the central and northern highlands, and in the western and southwest regions of Ethiopia, excluding the pastoral regions of Somali and Afar regions (Figure 5). For instance, in 1998, most part of Ethiopia particularly in the major crop producing areas of Amhara, Tigray, Benishangul Gumuz, Gambela, and Southern Nations, 
Nationalities, and Peoples' region (SNNPR) show the prevalence of severe to extreme drought conditions. The multitemporal drought maps showed a poor vegetation health and incidence of drought event two years in a row in
Amhara and Tigray regions, in the years 2009 and 2010. In contrast, the cropping seasons of 2001, 2004, 2007, and 2013 show normal vegetation conditions with VCI threshold values greater than 50 per cent implying a good crop harvest.
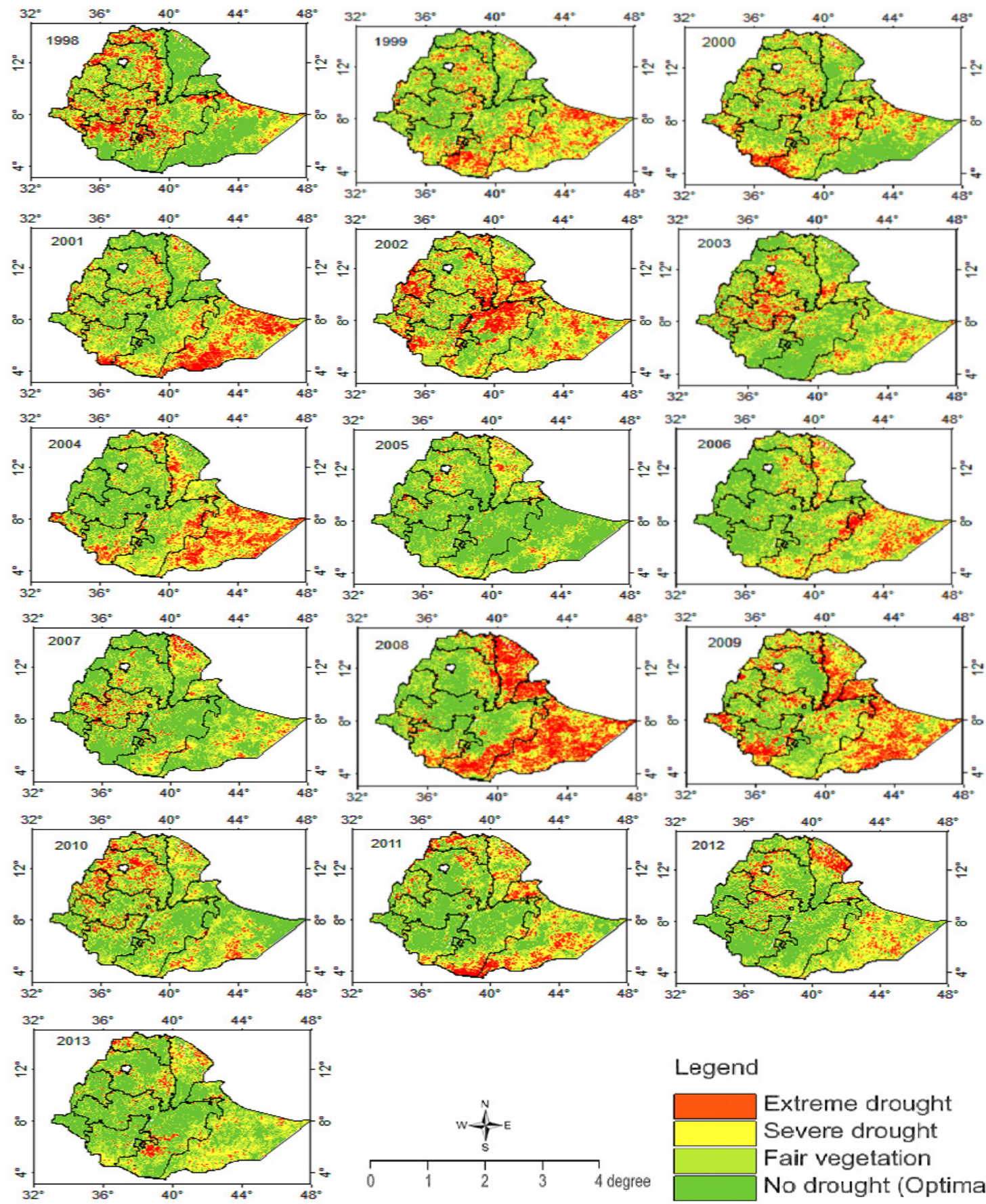

Legend
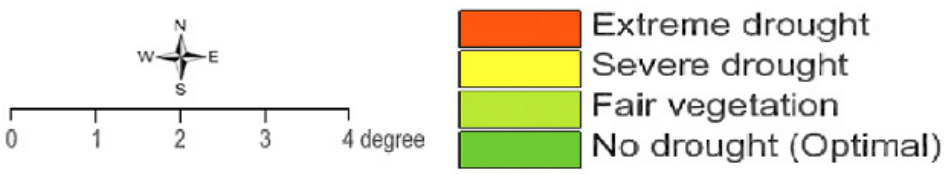

gure 5: VCI-based agricultural drought maps for the growing season for the period 19982013. 
The spatial aspect of agricultural drought was further analyzed by looking at the start and end of the crop growing season. VCI-based agricultural drought maps were thus constructed for the start (June) and end (August) of the cropping season as shown in Figure 6 and 7. A nationwide snapshot of the spatial agricultural drought maps show severe to extreme vegetation stress (indicated by red \& yellow color) at the start of the crop growing season for the years 1999 , 2002, 2003, 2004, and 2009 (Figure 6).
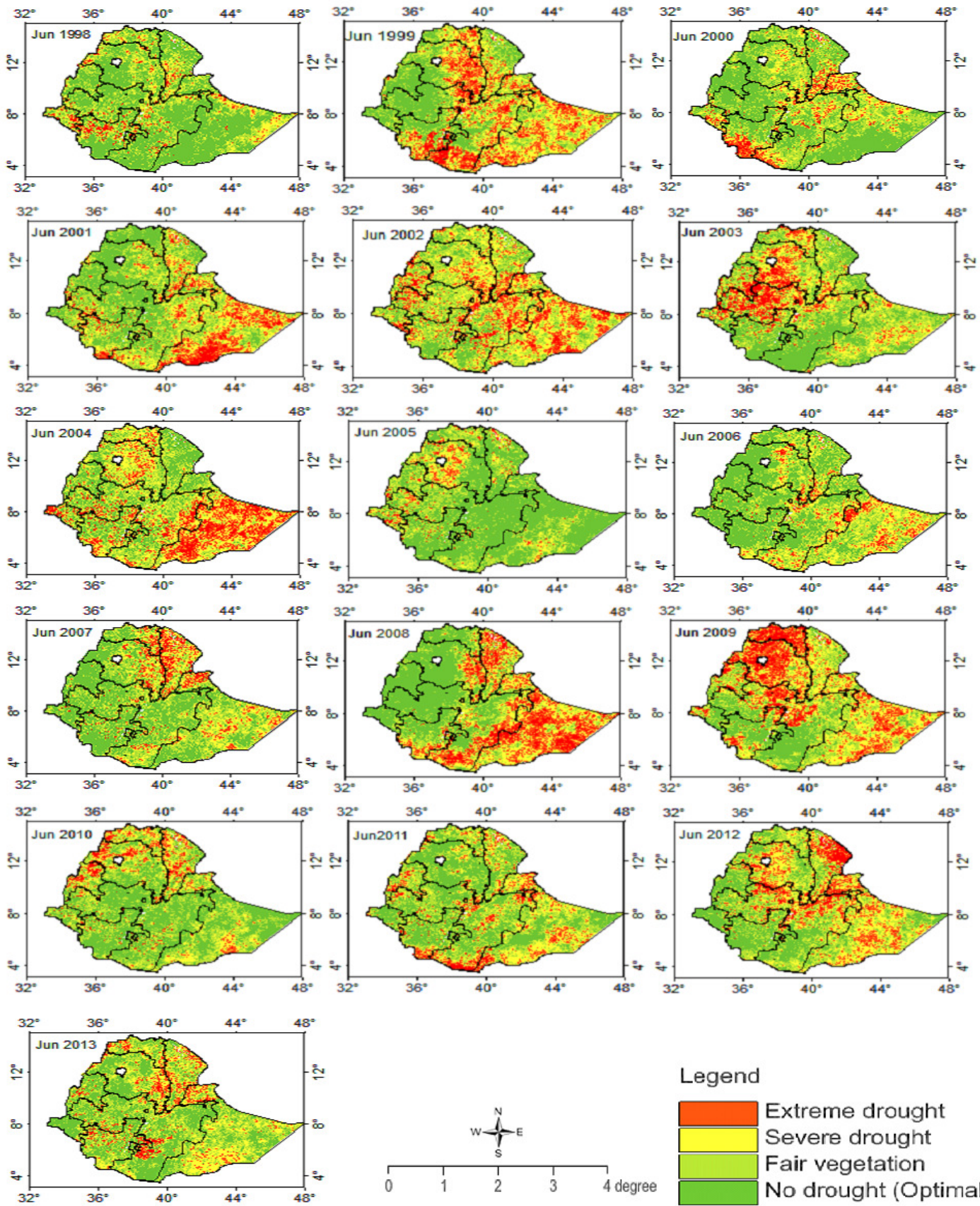

Legend

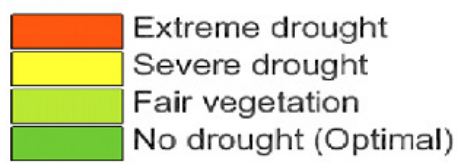

Figure 6: VCI-based agricultural drought maps at the start of the cropping season, June, for the period 1998-2013 
Similarly, VCI-based agricultural drought map for the end of the crop growing season, August, were produced as shown in Figure 7. The spatial agricultural drought maps reveal drought events at the end of August for the years 1998, 2000, 2002, and 2010 in the major Ethiopian crop producing regions (Figure 7).
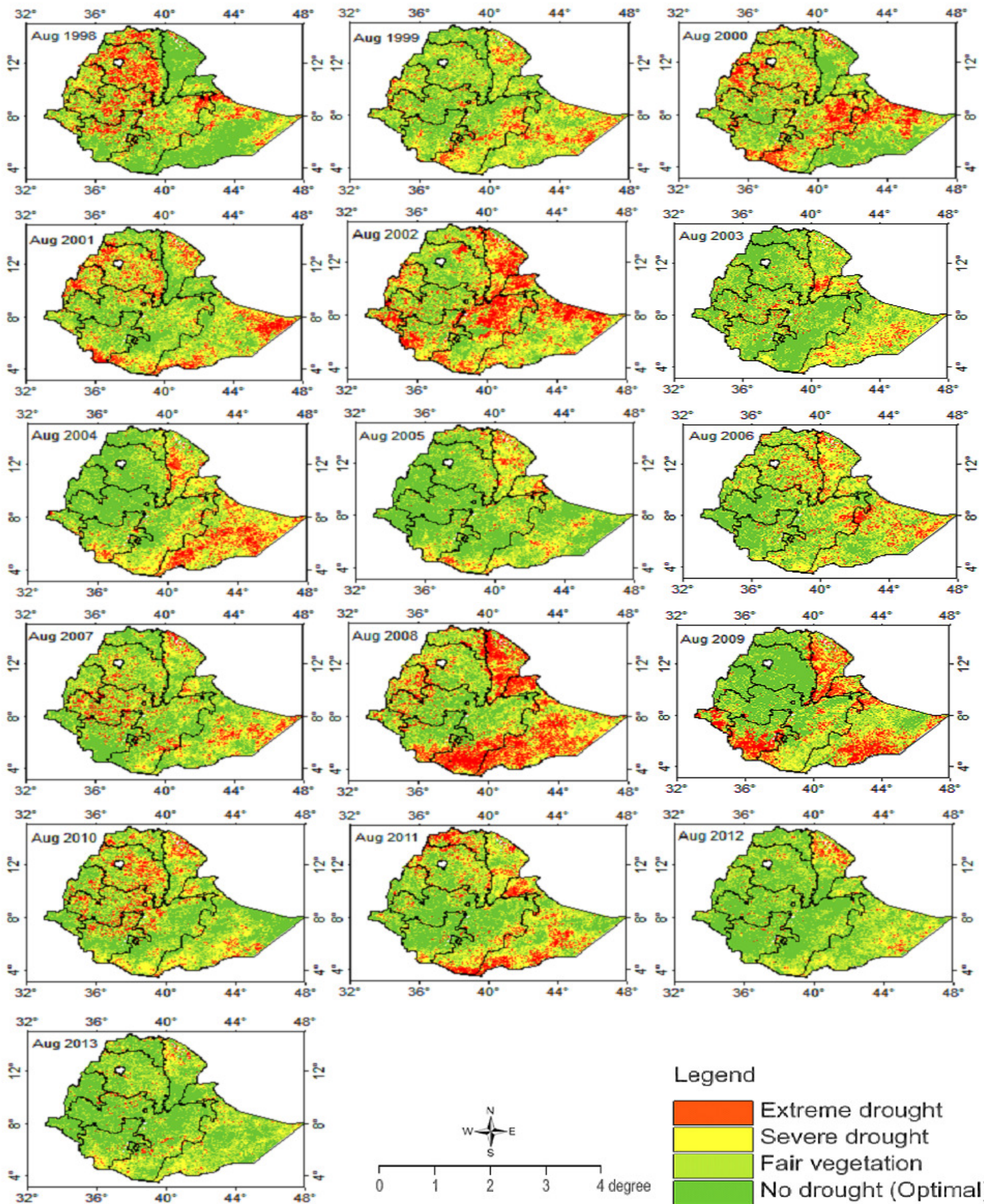

Legend

Figure 7: VCI-based agricultural drought maps at the end of the cropping season, August, for the period 1998-2013 
The findings of the analysis by differentiating over the crop cycles (Figure 6 and 7) provide additional insight on the main reasons behind the poor performance of crops, which resulted in drought conditions. Accordingly, the analysis for the start of the crop growing season showed agricultural drought events for the years 1999, 2002, 2003, 2004, and 2009 due to delay of rainfall at the beginning of the crop growing season. While, the analysis for the end of the crop growing season reveal drought events that caused crop failure due to rainfall failure towards the end of the crop growing period.

Furthermore, identification of a drought event was also done by looking
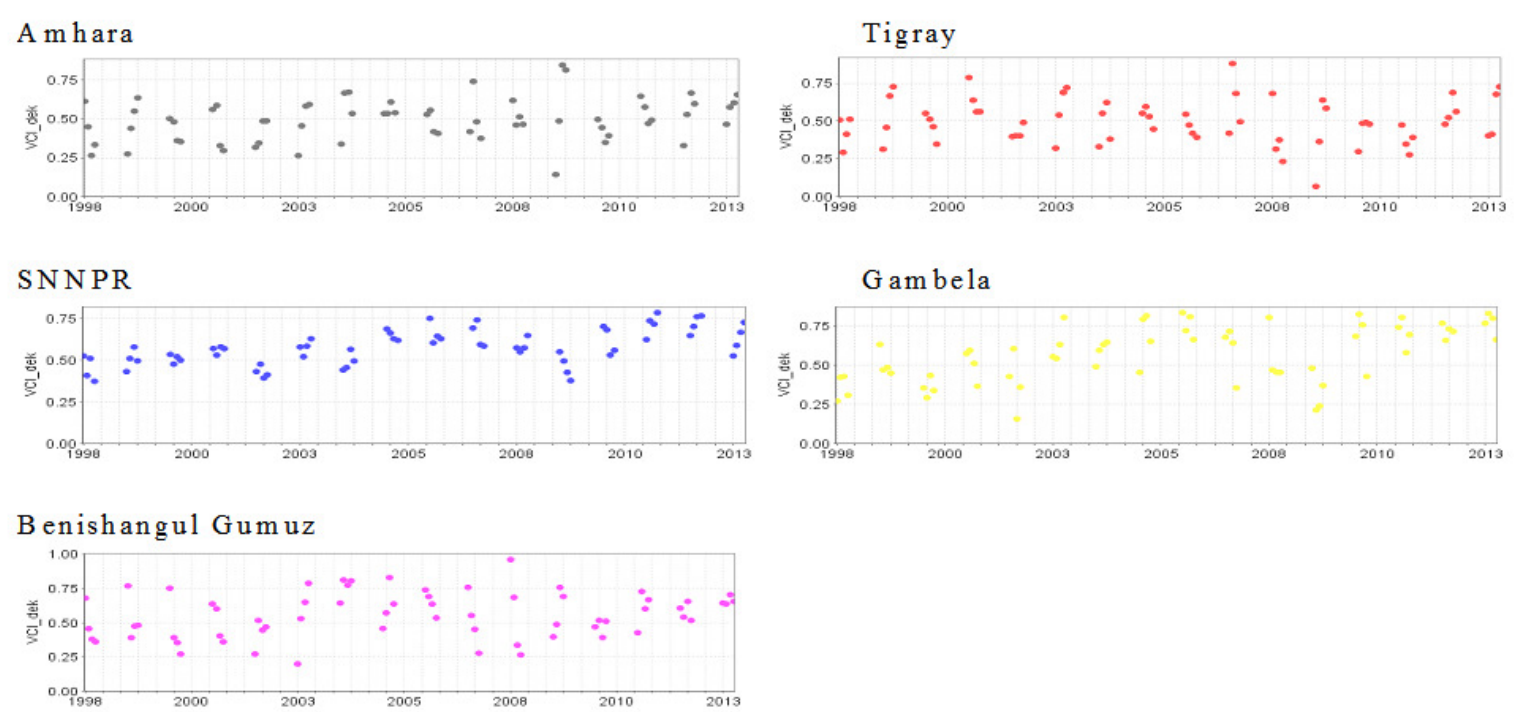

at the VCI-dekadal values over the whole crop growing season $\left(16^{\text {th }}\right.$ to $27^{\text {th }}$ dekad $)$. Four nationwide droughts were observed during the years 1998, 2000, 2002, and 2009 as almost all the dekadal VCI values for the crop growing season are less than 35 per cent (Figure 8). The figure reveals severely lower VCI values throughout the crop growing season during these periods. The countrywide extent of these drought events reflects the regional scale of these droughts that affected all major crop producing regions in the country. In addition to the nationwide drought events, it observed that the Amhara and Tigray regions were also hit by drought during the cropping season of 2010 that affected crop production.

Figure 8: Dekadal VCI values on agricultural land for major regions for the growing season

\section{Temporal Agricultural Drought Trend Assessment using RFE}

The temporal pattern of agricultural drought per administrative region on crop areas was further investigated using TAMSAT 10-day rainfall estimates (RFE) for the period 1998 to 2013. The first 13 and last 10 dekades of the calculated year are considered as dry season based on Ethiopian climatology, except for the southern and south-eastern lowlands of the country. Based on Eerens and Haesen (2013) definition of statistical parameters in SPIRITS, the ADav RFE values are used to determine rainfall anomalies and to examine the temporal aspect of drought. The rainfall estimates on crop areas for the major crop producing regions in Ethiopia is shown in Figure 9.

Based on the ADav RFE several drought events were identified, 1998, 
2002, 2004, and 2009 as indicated by the negative rainfall anomalies (Figure 9). Looking at regional level, rainfall was extremely low during the end of the growing period in Tigray region during the years 2002, 2003, 2004, 2009 and 2013 that affected agriculture practices in the region. Similarly, in Amhara region rainfall was extremely low at the end of the rainy season in the years 2002, 2004, and 2009. Furthermore, the temporal analysis indicated that rainfall was far below average rainfall at the commencement of the cropping season for the years 2002, 2003, 2010, and 2013 in Benishangul Gumuz, Gambela, and SNNPR regions as it is clearly indicated by negative rainfall anomalies.
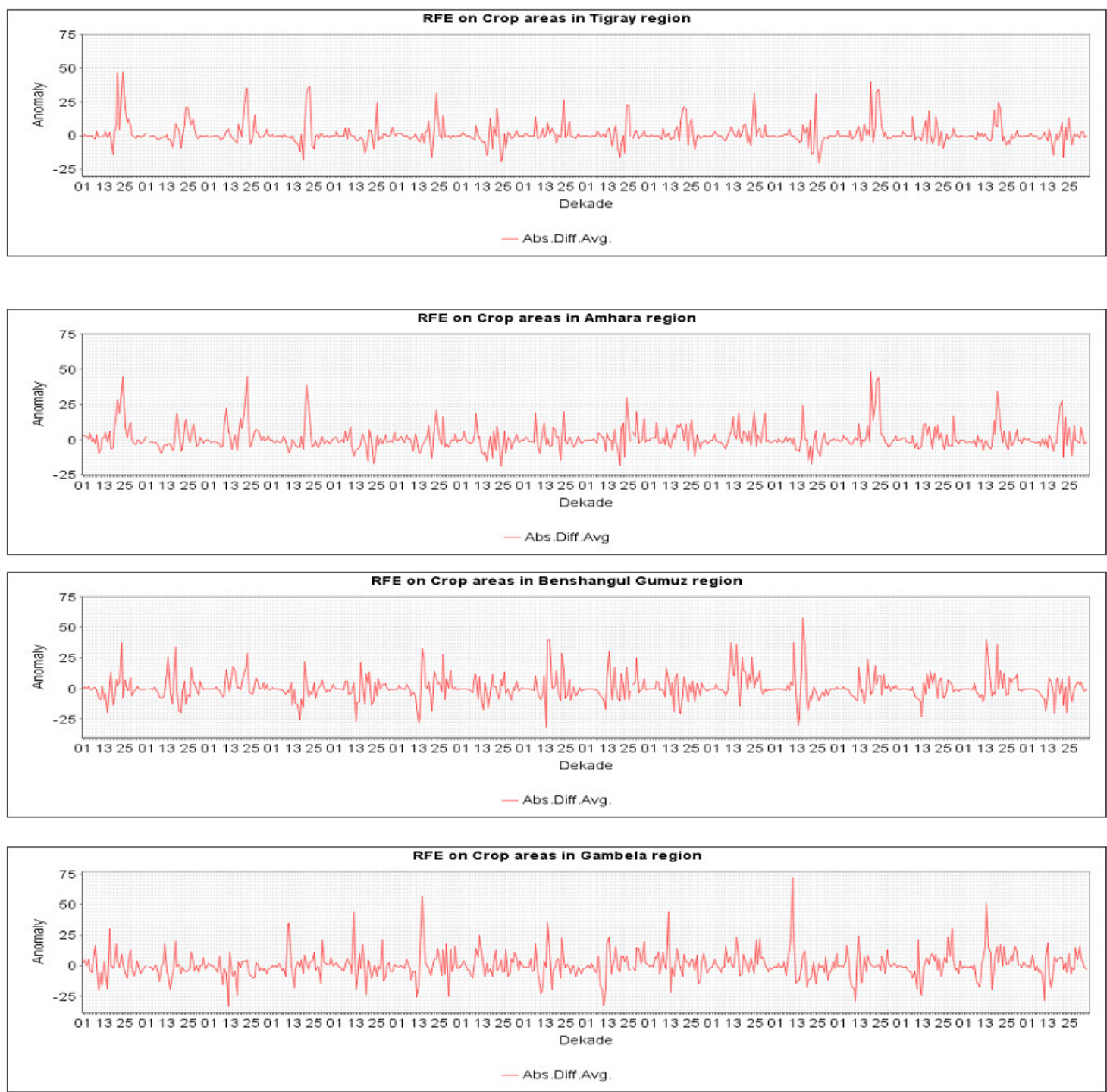

Figure 9: TAMSAT dekadal rainfall estimates on crop areas for the major crop producing regions; $1998-2013$

\section{Discussion}

Agricultural drought primarily indicates the deficiency of rainfall compared to normal rainfall condition in a given region. Consequently, the temporal pattern of vegetation condition during the crop growing season was assessed using Absolute Difference Average NDVI for the major crop producing regions in Ethiopia. 
Subsequently, several drought episodes were identified in Ethiopia using the ADav NDVI anomalies. The temporal analysis showed a significant negative NDVI anomaly for the major crop producing regions during the specified cropping periods indicating nationwide drought conditions. Furthermore, the multi-temporal analysis indicated occurrence of drought events in the northern highlands of Ethiopia (Amhara and Tigray regions) during the end of the crop growing season of 1998, 2002, and 2009 which resulted in crop failure.

The spatial-temporal aspect of agricultural drought in Ethiopia was further investigated by differentiating the crop cycles into the start, the end, and during the whole crop growing season using VCI. Kogan's (1995a) VCI classification was applied to identify drought events during the crop growing season (see Table 1). The temporal VCI maps during the crop growing season show a continuous drought in different areas of the major crop producing regions due to failure of timely rainfall at the start or towards the end of the cropping growing season.

A country-wide drought conditions were observed during the crop growing periods of 1998, 2000, 2002, 2009, and 2010 in the central and northern highlands, and in the western and southwest regions of Ethiopia, excluding the pastoral regions of Somali and Afar regions. Consequently, agricultural practices in the major crop producing regions were affected. A brief internet search for drought in Ethiopia during 1999-2011, produced hits at news media and aid organizations for every year, except 2001 (Viste et al., 2013). For instance, during the 2000, 2002/2003, and 2009 extreme drought periods, about $10.5,13$, and 5 million people were affected in the drought stricken areas of the country and depended on foreign food aid respectively. Refereeing to the 2000 drought episode, Bhalla (Bhalla, 2000) reported that six children under five years old are dying each day due to severe malnutrition in some of the areas worsthit by the drought in Ethiopia. The years 2000, 2002 and 2009 were identified as dry in most of Ethiopia by Viste et al. (2013). The VCI-based multi-temporal agricultural drought maps for the crop growing season further show that most of the drought events have been geographically concentrated in the central and northern highlands of Ethiopia, particularly in Amhara and Tigray. Similar results were reported by Ramakrishna and Demeke (2002). In contrast, healthy vegetation condition were observed over the cropping seasons of 2001, 2004, 2007, and 2013 implying a good crop harvest. The normal conditions during these cropping periods are associated with adequate rainfall conditions during the main rainy season leading to healthy vegetation condition as indicated in Figure 9.

In the Ethiopian agricultural setting, agricultural practices in times of sowing and harvesting have a profound impact in shaping the NDVI patterns (Gebrehiwot et al., 2011). Looking only at the vegetation condition over the whole crop growing season can conceal the main causes of crop failure at the different crop cycles. Accordingly, the condition of crop performance was assessed by differentiating over the crop cycles. The temporal analysis for the start of the crop growing season showed agricultural drought events for the years 1999, 2002, 2003, 2004, and 2009. This indicates the occurrence of vegetation stress as a result of rainfall delay at the commencement of the crop growing season. The temporal VCI maps for the start of the growing season further shows that the central, eastern and southern parts of Tigray; north and south Wello, north Shewa, and 
west and east Gojam of the Amhara region are the main areas that suffer a high intensity of vegetation stress at the start of the cropping period. Similarly, the VCI-based agricultural drought map for the end of the crop growing season reveal drought events that caused harvest failure for the years 1998, 2000, 2002, and 2010 in the crop producing regions due to rainfall failure towards the end of the crop growing period.

As an alternative, the temporal pattern of agricultural drought condition was further investigated using TAMSAT 10-day rainfall estimates (RFE). Accordingly, several drought events were identified, 1998, 2002, 2004, and 2009 indicating a substantial effect on agricultural production in the major crop producing region. Interestingly, this result corresponds well with the VCIbased drought events.

In general, the spatial and temporal drought analysis at the start, end and whole crop growing season demonstrates that the VCI-based drought analysis is very useful in detecting and monitoring agricultural drought at a national level. The analysis showed different causes for the nation-wide drought events occurred in the years 1998, 2000, 2002, 2009, and 2010. For instance, the 1998 and 2000 and 2010 drought events occurred due to rainfall failure at the critical stage (end) of the crop growing season, while 2009 drought condition occurred due to failure of timely rainfall at the commencement of crop growing. However, the year 2002 drought event occurred due to a long dryspell over the whole crop growing season.

\section{Conclusions}

The study investigates the spatial and temporal aspect of agricultural drought in Ethiopia during the crop growing season using VCI and Absolute Average Difference. Kogan's (1995a) VCI classification threshold was employed for the identification of agricultural drought events. We applied innovative new software (SPIRITS, freely available) package with a complete range of built-in functionalities that enabled us to process huge amounts of data in an efficient and consistent way. Subsequently, we are able to integrate two spatial datasets, a land cover map and Ethiopia's regional boundaries, to extract statistical data over crop areas and examine agricultural drought over space, which we believed makes the paper novel.

Though the indicators applied are different, to the best our knowledge Rojas et al. (2011) are the only authors who integrated a land cover map and administrative boundaries to evaluate the likelihood of agricultural drought incidence for the African continent. However, identification of drought at the continent (Africa) level can conceal drought areas at the sub-national levels (region in our case) within a country. Moreover, there are considerable spatial variations in rainfall within a country. In such conditions spatial variation in agricultural drought within a country is often overlooked with a continent (Africa) level analysis. This indicates the importance of conducting drought analysis that aids to accurately capture the spatial dimension of agricultural drought at a country level. Consequently, as Rojas et al. (2011) also suggested, we investigated agricultural drought by increasing the spatial resolution to the regional level within national states. Moreover, we use detailed information on the different crop cycles, which gives more insight.

Accordingly, the study provides useful information on the major historical agricultural drought events for the major crop producing areas over the period 1998 to 2013. The study was able to geographically identify the regions 
exposed to recurrent cycle of drought. Accordingly, the analysis indicated the central and northern highlands of Ethiopia, particularly the Amhara and Tigray regions, as the most vulnerable agricultural production regions. Historically, the two regions have been known as the most severely affected regions during the well-known Ethiopian famine periods. Thus, a slight drought that result a failure in crop harvest can undermine household food security and jeopardized development activities in the areas.

As it is clearly shown in the above discussion, the VCI-based analysis for the crop growing season accurately indicates the onset, spatial, and temporal dynamics of agricultural drought in Ethiopia. By and large, the study provides evidence that VCI-based drought analysis is an important tool for monitoring areas potentially affected by agricultural drought at the national level during the crop growing season. This will aid policy makers for making decisions, implementing measures to mitigate adverse consequences, and implement localized programs that aim to address household food insecurity in the affected areas of the country.

\section{Acknowledgements}

We are thankful to the Flemish Institute for Technological Research NV (GEONETCast - VGT4AFRICA) and Reading University (UK) for their kind help in providing the SPOT images and TAMSAT RFE used in this study. The authors also thank the Editor and the anonymous referee for their constructive comments and suggestions.

\section{Reference}

Anyamba, A., Tucker, C.J. and Eastman, J.R. (2001). NDVI anomaly patterns over Africa during the
1997/98 ENSO warm event. Int. J. Remote Sens., 22: 1847-1859.

Araya, A. and Stroosnijder, L. (2011). Assessing drought risk and irrigation need in northern Ethiopia. Agricultural and Forest Meteorology, 151: 425-436.

Atzberger, C. and Eilers, P.H.C. (2011). A time series for monitoring vegetation activity and phenology at 10-daily time steps covering large parts of South America. Int. J. Digit. Earth. 4: 365-386.

Bajgirana, P.R., Darvishsefatb, A.A., Khalilic, A. and Makhdoum, M.F. (2008). Using AVHRR-based vegetation indices for drought monitoring in the Northwest of Iran. J. Arid Environ., 72: 10861096.

Benson, C.C. and Clay, E. (1998). The impact of drought on sub-Saharan African economies. World Bank Technical Paper No. 401, Washington, DC

Bewket, W. and Conway, D. (2007). A note on the temporal and spatial variability of rainfall in the droughtprone Amhara region of Ethiopia. Int. J. Climatol., 27: 1467-1477.

Bhalla, N. (2000). Children die in Ethiopian drought. http://news.bbc.co.uk/2/hi/africa/69 6160.stm. Accessed 26 November 2014.

Bhuiyan, C., Singh, R.P. and Kogan, F.N. (2006). Monitoring drought dynamics in the Aravalli region (India) using different indices based on ground and remote sensing data. Int. J. Appl. Earth Obs., 8: 289-302.

Boken, V.K. (2005). Agricultural drought and its monitoring and prediction: some concepts. In: Boken, V.K., Cracknell, A.P., Heathcote, R.L. (Eds.), Monitoring and Predicting Agricultural Drought: A Global 
Study. Oxford University Press, New York, pp. 3-10.

Brown, J.F., Wardlow, B.D., Tadesse, T., Hayes, M.J. and Reed, B.C. (2008). The Vegetation Drought Response Index (VegDRI): A new integrated approach for monitoring drought stress in vegetation. GISci. Remote Sens. 45: 16-46.

Collier, P., Conway, G. and Venables, P. (2008). Climate Change and Africa. Oxford Rev. Econ. Pol., 24, 337353.

Conway, D. and Schipper, E.L.F. (2011). Adaptation to climate change in Africa: Challenges and opportunities identified from Ethiopia. Global Environ. Chang. 21: 227-237.

Degefu, W. (1987). Some aspects of meteorological drought in Ethiopia. In: Glantz, M.H. (Ed.), Drought and hunger in Africa denying famine a future. Cambridge University Press, Cambridge, pp. 23-36.

Diao, X. (2010). Economic importance of agriculture for sustainable development and poverty reduction: The case study of Ethiopia. Global forum on agriculture 29-30 November 2010, Policies for agricultural development, poverty reduction and food security OECD Headquarters, Paris.

Dinku, T., Ceccato, P., Grover-Kopec, E., Lemma, M., Connor, S.J. and Ropelewski, C.F. (2007). Validation of Satellite Rainfall Products over East Africa's Complex Topography. Int. J. Remote Sens., 28, 1503-1526.

Diro, G.T., Grimes, D.I.F., Black, E., O’Neill, A., Pardo-Iguzquiza, E. (2009). Evaluation of reanalysis rainfall estimates over Ethiopia. Int. J. Climatol., 29: 67-78.

Domenikiotis, C., Spiliotopoulos, M., Tsiros, E., Dalezios, N.R. (2004).
Early cotton production assessment in Greece based on a combination of the drought vegetation condition index (VCI) and the bhalme and mooley drought index (BMDI). Int. J. Remote Sens., 25: 5373-5388.

Dracup, J.A., Lee, K.S. and Paulson, E.G.J. (1980). On the definition of droughts. Water Resour. Res., 16: 297-302.

Eerens, H. and Haesen, D. (2013). Software for the Processing and interpretation of remotely sensed image time series. User's manual, Version: 1.1.1, VITO.

Eerens, H., Haesen, D., Rembold, F., Urbano, F., Tote, C. and Bydekerke, L. (2014). Image time series processing for agriculture monitoring. Environ. Modell. Softw. 53: 154-162.

Engida, A.N. and Esteves, M. (2011). Characterization and disaggregation of daily rainfall in the Upper Blue Nile Basin in Ethiopia. J. Hydrol. 399: 226-234.

Falco, S.D. (2012). Managing Environmental Risk in Presence of Climate Change: The Role of Adaptation in the Nile basin of Ethiopia. 86th Annual Conference of the Agricultural Economics Society, University of Warwick, United Kingdom.

Ferris-Morris, M. (2003). Planning for the Next Drought: Ethiopia Case Study. USAID, Washington.

Gebrehiwot, T. and van der Veen, A. (2013). Farm Level Adaptation to Climate Change: The Case of Farmer's in the Ethiopian Highlands. Environ Manage., 52: 29-44.

Gebrehiwot, T., van der Veen, A. and Maathuis, B. (2011). Spatial and temporal assessment of drought in the Northern highlands of Ethiopia. 
Int. J. Appl. Earth Obs., 13: 309321.

Gitelson, A.A., Kogan, F.N., Zakarin, E., Spivak, L. and Lebed, L. (1998). Using AVHRR data for quantitative estimation of vegetation conditions: calibration and validation. $A d v$. Space Res., 22: 673-676.

Gray, C. and Muller, V. (2012). Drought and population mobility in rural Ethiopia. World Dev., 40: 134-145.

Heim, R.R. (2002). A review of twentieth-century drought indices used in the United States. Am. Meteorol. Soc. 83: 1149-1165.

Jacobs, T., Piccard, I., Bydekerke, L. and Gontier, E. (2006). S10 NDVI. In: Bartholomé, E. (Ed.), VGT4Africa user manual. First edition. European Communities, Luxembourg, pp. 97-105.

Ji, L. and Peters, A.J. (2003). Assessing vegetation response to drought in the northern Great Plains using vegetation and drought indices. Remote Sens. Environ. 87: 85-98.

Kogan, F.N. (1990). Remote sensing of weather impacts on vegetation in non-homogeneous areas. Int. J. Remote Sens. 11, 1405 - 1419.

Kogan, F.N. (1995a). Application of vegetation index and brightness temperature for drought detection. Adv. Space Res. 15: 91-100.

Kogan, F.N. (1995b). Droughts of the late 1980s in the United States as derived from NOAA polar-orbiting satellite data. B. Am. Meteorol. Soc. 76: 655-666.

Kogan, F.N. (1997). Global drought watch from space. Am. Meteorol. Soc. 78, 621-636.

Kogan, F.N., Gitelson, A., Edige, Z., Spivak, I. and Lebed, L. (2003). AVHRR-based spectral vegetation index for quantitative assessment of vegetation state and productivity: calibration and validation.
Photogramm. Eng. Rem. S., 69: 899-906.

Liu, W.T. and Kogan, F.N. (1996). Monitoring regional drought using the Vegetation Condition Index. Int. J. Remote Sens. 17: 2761 - 2782.

Nicholson, S.E., Davenport, M.L. and Malo, A.R. (1990). A comparison of vegetation response to rainfall in the Sahel and East Africa using normalized difference vegetation index from NOAA-AVHRR. Climate Change 17: 209-241.

Omondi, P.A., Awange, J.L., Forootan, Ogallo, L.A., Barakiza, R., Girmaw, G.B., Fesseha, I., Kululetera, V., Kilembe, C., Mbati, M.M., Kilavi, M., King'uyu, S.M., Omeny, P.A., Njogu, A., Badr, E.M., Musa, T.A., Muchiri, P., Bamanyan, D. and Komutungao, E. (2014). Changes in temperature and precipitation extremes over the Greater Horn of Africa region from 1961 to 2010. Int. J. Climatol. 34: 1262-1277.

Ramakrishna, G. and Demeke, A. (2002). An empirical analysis of food insecurity in Ethiopia: The case of north Wello. Afr. Dev. 27, 127-143.

Rasmusson, E.M. (1988). Global climate change and variability: effects on drought and desertification in Africa. In: Glantz, G.H. (Ed.), Drought and Hunger in Africa. University Press, New York, pp. 436.

Ringler, C., Zhu, T., Cai, X., Koo, J. and Wang, D. (2010). Climate change impacts on food security in subSaharan Africa. Insights from comprehensive climate change scenarios. IFPRI Discussion Paper 01042.

Robinson, S., Strzepek, K. and Cervigni, R. (2013). The cost of adapting to climate change in Ethiopia: Sectorwise and macro-economic 
estimates. Ethiopia Strategy

Support Program II (ESSP) working Paper 53. EDRI and IFRI. Addis Ababa.

Rojas, O., Vrieling, A. and Rembold, F. (2011). Assessing drought probability for agricultural areas in Africa with coarse resolution remote sensing imagery. Remote Sens. Environ. 115: 343-352.

Tonini, F., Lasinio, G.J. and Hochmair, H.H. (2012). Mapping return levels of absolute NDVI variations for the assessment of drought risk in Ethiopia. Int. J. Appl. Earth Obs. 18: 564-572.

Tucker, C.J. (1979). Red and photographic infrared linear combinations for monitoring vegetation. Remote Sens. Environ. 8, 127-150.

Tucker, C.J., Newcomb, W.W., Los, S.O. and Prince, S.D. (1991). Mean and inter-annual variation of growingseason normalized difference vegetation index for the Sahel 1981-1989. Int.J. Remote Sens. 12: 1133-1135.

Tucker, C.J., Vanpreat, C.L., Sharman, M.J., Van Ittersum, G. (1985). Satellite remote sensing of total herbaceous biomass production in the Senegalese Sahel: 1980-1984. Int. J. Remote Sens. 7, 233-249.

Unganai, L.S. and Kogan, F.N. (1998). Drought monitoring and corn yield estimation in southern Africa from AVHRR data. Remote Sens. Environ. 63: 219-232.

Viste, E., Korecha, D. and Sorteberg, A. (2013). Recent drought and precipitation tendencies in Ethiopia. Theor. Appl. Climatol., 112: 535551.

Wardlow, B.D., Anderson, M.C., J. P. and Verdin, P. (2012). Remote sensing of drought: Innovative monitoring approaches. FL: CRC Press, Boca Raton.

WFP (2009). Food security and vulnerability in selected towns of Tigray Region, Ethiopia. WFPEthiopia, Vulnerability Assessment and Mapping (VAM).

Wilhite, D.A. (2000). Drought as a natural hazard: concepts and definitions. In: Wilhite, D.A. (Ed.), Drought: A Global Assessment, vol. 1. Routledge, New York, pp. 318.

Yagci, A.L., Deng, M., Di, L., Han, W. and Peng, C. (2011). Vegetation index based technique for global agricultural drought monitoring. 5th International Conference on Recent Advances in Space Technologies, pp. 137-141.

Yang, L., Wylie, B.K., Tieszen, L.L. and Reed, B.C. (1998). An analysis of relationships among climate forcing and time-Integrated NDVI of grasslands over the U.S. northern and central great plains. Remote Sens. Environ. 65, 25-37.

Zhang, N., Hong, Y., Qin, Q. and Liu, L. (2013). VSDI: a visible and shortwave infrared drought index for monitoring soil and vegetation moisture based on optical remote sensing. Int. J. Remote Sens. 34, 4585-4609. 